Original Article

\title{
Application of Factorial Design for Optimization of PVC-HPMC Polymers in Matrix Film Ibuprofen Patch-Transdermal Drug Delivery System
}

\author{
Galih Pratiwi ${ }^{1}$, Susi Susanti ${ }^{1}$, and Shaum Shiyan ${ }^{2^{*}}$ \\ ${ }^{1}$ Department of Pharmacy, STIKES 'Aisyiyah Palembang, Sumatera Selatan Indonesia, 30152 \\ 2 Department of Pharmacy, Faculty of Mathematics and Natural Sciences, Universitas Sriwijaya, Indralaya \\ (OI) Sumatera Selatan Indonesia, 30662 \\ *Corresponding Author: Shaum Shiyan email: shaumshiyan@unsri.ac.id
}

Received: 13 December 2020; Revised: 13 January 2021; Accepted: 4 February 2021; Published: 14 February 2021

\begin{abstract}
Ibuprofen is a non-steroidal anti-inflammatory drug (NSAID) class of drugs, and oral use can cause side effects. Transdermal patch dosage forms are useful for minimizing side effects on oral administration. Transdermal patches are formulated using a special membrane that can control drug release in the matrix system. This study was intended to determine the characteristics of the resulting patch, the optimum composition of the formula, and the profile of the release of transdermal ibuprofen release. The film matrix optimization on the ibuprofen patch formulation uses design of experiment (DoE) approach using factorial design $2^{2}$. The mixture of polyvinyl pyrrolidone (PVC) and hydroxypropyl methylcellulose (HPMC) components gives a pleasant texture, and the release results in vitro show a proper and controlled release of the ibuprofen patch. Based on the research, it can be concluded that the patch has excellent characteristics with a good texture so that the development time is long with the optimum formula of chitosan and HPMC, as well as having a proper and controlled release profile.
\end{abstract}

Keywords: Ibuprofen, optimization, design of experiment, factorial design, PVP, HPMC, transdermal patch

\section{INTRODUCTION}

Ibuprofen is a non-steroidal anti-inflammatory drug (NSAID) group with a mechanism of action inhibiting the synthesis of COX-1 and COX-2. Oral use can cause side effects such as stomach discomfort, irritation, nausea, vomiting, and gastric erosion [1]. Many ibuprofen formulations have been developed to minimize the side effects of drugs on the gastrointestinal tract. Side effects caused by ibuprofen can be prevented by making a transdermal dosage form. The ibuprofen gel given in the transdermal route has been formulated [2]. However, the gel form formulation still has disadvantages, such as drug release, texture, and comfort in topical use. The transdermal route can increase the bioavailability of drugs because they do not pass through the first pass of metabolism and provide consistent delivery over a long time [3].

Transdermal patch formula is an attractive solution to the problem of side effects and the development of drug delivery systems. Patches have the form of a thin layer, such as plaster that is sufficiently applied to the skin. Patch preparations will improve patient adherence to therapy in the long term [1]. Patch formulations can deliver specific treatment doses through the skin (transdermal) to blood circulation and reduce the risk of gastric irritation by ibuprofen, making it more effective and safe in its use [4,5]. Besides, it can minimize side effects when compared to oral administration [1]. 
This research develops a film matrix because this type will form a thin and elegant patch preparation. It is hoped that the transdermal patch is more convenient to use and a smooth, fast, and inexpensive manufacturing process [6]. Patches can guarantee the accuracy of doses compared to gel or ointment preparations [7]. Matrix-forming polymers have an essential role in transdermal patch preparations. Polymers function to control the rate of drug release from preparations [8,9]. Hydroxypropyl methylcellulose (HPMC) polymer has been chosen because it is easily hydrated by water, expanding, and accelerating the release of drugs from its base [10]. The use of HPMC polymers without a rate controlling membrane will quickly release the drug during the dissolution test [11]. Therefore, a polymer combination is needed so that the release does not occur quickly and can be arranged.

The combination of polymers will affect the quality of the resulting patch matrix. Hydrophilic or hydrophobic mixtures of polymers largely determine drug release more effectively than the matrix [12,13]. The combination of polyvinyl pyrrolidone (PVP) and HPMC polymers is expected to help release the drug to improve the quality of the ibuprofen patch. To the best of scientific knowledge, there is no optimization model for these two mixtures of materials. Therefore, an optimization of the mixture of the two polymers was carried out using a design of experiment (DoE) approach with simple statistical modeling, namely factorial design $2^{2}$. This study's success is expected to provide information on optimization modeling and the development of pharmaceutical preparations using polymer blends in the patch formulation method as an alternative to improve the bioavailability of drugs.

\section{MATERIALS AND METHODS}

\subsection{Materials}

As an active ingredient used in the formulation, Ibuprofen was obtained from PT Phapros Tbk, Semarang Indonesia. Polymers in the form of polyvinyl pyrrolidone (PVP K-30) were purchased from Fajar Kimia, Bogor Indonesia. Materials such as ethanol, HPMC, and PEG 400 were obtained from Bratachem, Jakarta Indonesia, and propylene glycol from Dow Chemical.

\subsection{Determination of Experimental Designs with Factorial Designs $2^{2}$}

The combination of PVP and HPMC polymers in the ibuprofen transdermal patch formulation was designed using a factorial design $2^{2}$. Factors as two independent variables are PVP (A) and HPMC (B). The responses determined in the evaluation included weight uniformity $\left(R_{1}\right)$, thickness $\left(R_{2}\right)$, and swelling index $\left(R_{3}\right)$, and humidity $\left(R_{4}\right)$. The number of trial runs, modeling analysis, and optimization is determined using the design-expert 12 series free trial software. Lower PVP range values are used $2 \%$ and above $6 \%$. Lower range values for HPMC polymers are $2 \%$ and above $10 \%$.

Table 1. Complete design with levels and factors on factorial designs $2^{2}$

\begin{tabular}{ccccc}
\hline \multirow{2}{*}{ Formula } & \multicolumn{2}{c}{ Level } & \multicolumn{2}{c}{ Polymer composition (\%) } \\
\cline { 2 - 5 } & A: PVP & B: HPMC & PVP & HPMC \\
\hline run 1 & -1 & 1 & 2 & 10 \\
run 2 & -1 & -1 & 2 & 2 \\
run 3 & 1 & -1 & 6 & 2 \\
run 4 & 1 & 1 & 6 & 10 \\
\hline
\end{tabular}

\subsection{Ibuprofen Transdermal Patch Formulation}

Ibuprofen in the amount of $25 \mathrm{mg}$ was dissolved using ethanol solvent and added to a mixture of polyethylene glycol (PEG 400) and propylene glycol (PG). The homogeneous solution was transferred to the beaker glass, and a PVP-HPMC polymer mixture was added. The enhancer material used is propylene glycol, which is added to the mixture until it is homogeneous. The mold uses a petri dish coated with vaseline and backing. The matrix drying process is carried out at a temperature of $25-30 \mathrm{C}$ to dry. The resulting patch matrix is inserted in the container and stored. 


\subsection{Uniformity in Weights}

Weight uniformity evaluation is done to determine the weight of the patch preparation. Evaluation is carried out using patch preparations taken as much as 10, and each preparation is weighed and seen variations in weight [14].

\subsection{Evaluate the Thickness of the Patch Matrix}

Evaluate the thickness of the patch matrix. Thickness tests were carried out to determine the thickness of the patch on different polymer quantities, using calipers [15]. Patch thickness is measured at several different points, and then the average thickness, standard deviation, and coefficient of variation are determined to ensure the thickness of each patch [14].

\subsection{Swelling Index Assay}

The weighing was carried out on three patch matrices of each formula $\left(\mathrm{W}_{1}\right)$ and put in a container with a $5 \mathrm{~mL}$ phosphate buffer $\mathrm{pH}$ 6-8 solution. Patches are taken after a predetermined time interval (minutes 1, 2, 3, 4, and 5) and weighing $\left(\mathrm{W}_{2}\right)$. The measurement results are recorded as swelling results; then, the index value is calculated [16].

\subsection{Moisture Content Assay}

Each prepared patch was weighed (as initial weight) and stored in a desiccator containing silica gel at 30C for 24 hours. The patch is then re-weighed (as a final weight) [17].

\subsection{Folding Endurance Assay}

The folding endurance test aims to determine the folding capacity of the polymer patch. The folding endurance test is carried out by repeatedly folding the patch matrix at the same point until it is damaged [14]. Replication is done three times, then the average value and standard deviation of the results of the folding endurance measurements are calculated. Patch matrix is suitable if it has a value of folding resistance more than 300 times [18].

\subsection{Surface $\mathrm{pH}$}

$\mathrm{A} \mathrm{pH}$ evaluation is needed to ensure the $\mathrm{pH}$ of the patch surface with the skin. The test is carried out using $10 \mathrm{~mL}$ of $\mathrm{CO}_{2}$-free water added to the beaker glass that contains the patch and then allowed to stand for 1 hour. $\mathrm{pH}$ testing was carried out using a $\mathrm{pH}$ meter. Criteria for the $\mathrm{pH}$ range that can be tolerated for not irritating the skin is 4.5-6.5 [19].

\subsection{In Vitro Test for the Release of Ibuprofen}

The penetration test is carried out using a modified vertical type Franz diffusion cell. The donor portion contains ibuprofen transdermal patch preparations. The membrane is placed between the two compartments (donor and acceptor) with the dermis side facing the acceptor. The acceptor compartment contains a phosphate buffer ( $\mathrm{pH} 7.4$ ) of $15 \mathrm{~mL}$ and stirred at $600 \mathrm{rpm}$ at $37 \pm 0.5^{\circ} \mathrm{C}$ [20]. Observations were carried out for 120 minutes, and samples were taken at 10, 20, 30, 60, and 120 minutes each time $1 \mathrm{~mL}$ of sample was added with a $\mathrm{pH}$ phosphate buffer of $1 \mathrm{~mL}$. Samples were put into a $5 \mathrm{~mL}$ measuring flask and added phosphate buffer up to $5 \mathrm{~mL}$. Absorption is measured at the maximum absorption wavelength and determine the amount of drug that is penetrated using UV-Vis Genesys $10 \mathrm{~S}$ spectrophotometry (Thermo Scientific, USA).

\subsection{FTIR-ATR Profile}

Fourier transform infrared (FTIR) is a technique used to study the physical and chemical interactions between drugs and additives [21,22]. Each ibuprofen patch was measured using a Nicolet iS5 IR spectrophotometer (Thermo Scientific, USA) at wavenumbers 500-4000 $\mathrm{cm}^{-1}$.

\subsection{Statistical Analysis}

Data from the experimental design using factorial design $2^{2}$ were statistically analyzed and mathematical modeling using design-expert (DX) software (Stat-Ease Inc., Minneapolis, MN, USA). Each response evaluated was obtained by a contour plot and a mathematical equation for the observed factors. The equation obtained provides information about the effect of factors on the response by identifying each factor's positive and negative values. Contour plots are combined into superimposed / overlay plot contour plots, and this step is carried out to determine the optimum composition of the PVP combination and as a polymer. 


\section{RESULTS AND DISCUSSION}

\subsection{Modeling Using Factorial Design (FD) $2^{2}$}

The complete design of FD $2^{2}$ is obtained based on the values of the upper and lower ranges of orientation. A model for optimization using the DoE approach can provide accurate prediction results by evaluating parameters such as Press, $R^{2}$, adjusted $R^{2}$, predicted $R^{2}$, and adequate precision $[23,24,25]$. The model in each response meets the criteria if the difference between the adjusted $R^{2}$ and predicted $R^{2}$ values is not more than $0.2 . R^{2}$ values more than 0.7 and adequate precision values more than 4 . The results of multivariate analysis resulting from the four responses can be seen in Table 2.

Table 2. Statistical parameters for the model for weight uniformity response $\left(R_{1}\right)$, thickness $\left(R_{2}\right)$, swelling index $\left(\mathrm{R}_{3}\right)$, and humidity $\left(\mathrm{R}_{4}\right)$

\begin{tabular}{ccccccccc}
\hline & \multicolumn{8}{c}{ Statistical parameters } \\
\cline { 2 - 9 } Respons & SD & CV & Press & $R^{2}$ & $\begin{array}{c}\text { Adjusted } \\
R^{2}\end{array}$ & $\begin{array}{c}\text { Predicted } \\
R^{2}\end{array}$ & $\begin{array}{c}\text { Adequate } \\
\text { precision }\end{array}$ & $\begin{array}{c}\text { Status } \\
\text { model }\end{array}$ \\
\hline $\mathrm{R}_{1}$ & 0.03 & 0.65 & 0.01 & 0.9984 & 0.9951 & 0.9741 & 35.58 & significant \\
$\mathrm{R}_{2}$ & 0.18 & 3.96 & 0.27 & 0.9613 & 0.9420 & 0.8452 & 9.97 & significant \\
$\mathrm{R}_{3}$ & 0.12 & 1.84 & 0.12 & 0.9574 & 0.9361 & 0.8296 & 9.48 & significant \\
$\mathrm{R}_{4}$ & 2.07 & 28.86 & 34.13 & 0.9581 & 0.9372 & 0.8325 & 9.57 & significant \\
\hline
\end{tabular}

Response uniformity of weights $\left(\mathrm{R}_{1}\right)$ from the evaluation has an $R^{2}$ of more than 0.7 (0.9984), the difference between adjusted $R^{2}$ and predicted $R^{2}$ is 0.021 and the value of adequate precision (35.58). The thickness response $\left(R_{2}\right)$ has an $R^{2}$ value of more than $0.7(0.9613)$, the difference between the adjusted $R^{2}$ and the predicted $R^{2}$ is 0.0968 and the value of adequate precision (9.97). Development response ( $\left.\mathrm{R}_{3}\right)$ has an $R^{2}$ of more than $0.7(0.9574)$, adjusted $R^{2}$, and predicted $R^{2}$ are 0.1065 and adequate precision (9.48). Moisture response $\left(R_{4}\right)$ has an $R^{2}$ of more than 0.7 (0.9581), adjusted $R^{2}$, and predicted $R^{2}$ are 0.1047 and adequate precision (9.57).

Table 3. Transformation status, model type, and regression equation of the weight uniformity response $\left(R_{1}\right)$, thickness $\left(R_{2}\right)$, swelling index $\left(R_{3}\right)$, and humidity $\left(R_{4}\right)$

\begin{tabular}{cccc}
\hline Response & Transformation & Model & Regression \\
\cline { 2 - 3 }$R_{1}$ & None & Main effects & $\mathrm{R}_{1}=4.35-0.10 \mathrm{~A}-0.34 \mathrm{~B}$ \\
$\mathrm{R}_{2}$ & None & Reduced 2FI & $\mathrm{R}_{2}=4.63+0.65 \mathrm{AB}$ \\
$\mathrm{R}_{3}$ & None & Reduced 2FI & $\mathrm{R}_{3}=6.60+0.41 \mathrm{AB}$ \\
$\mathrm{R}_{4}$ & None & Reduced main effects & $\mathrm{R}_{4}=7.16-6.99 \mathrm{~A}$ \\
\hline
\end{tabular}

For the weight uniformity response, the main effects model is obtained. The thickness and swelling index have a reduced 2FI model, while humidity has a reduced main effects model. The transformation status and model equations obtained are listed in Table 3. Overall from the results of the analysis, all responses indicate a good model for predicting the optimal mixture composition of the formulated polymer.

\subsection{Analysis of Weights Uniform Response $\left(\mathbf{R}_{1}\right)$}

The final unit used in evaluating the uniformity of weights is the percent coefficient of variation $(\% \mathrm{CV})$. Data from 4 run experiments are scattered around diagonal lines on the normal plot of residuals curve (Fig. 1b), indicating that the data are normally distributed and qualify for the ANOVA test. A good model is also indicated from the absence of suggestions for transformation when fitting the model. The transformation of the equation model can be done if the value of $R^{2}$, the difference between adjusted $R^{2}$ and predicted $R^{2}$, and the value of adequate precision does not meet the requirements. It is hoped that the transformation following the recommendations in the program will improve the parameters and statistical test results. Based on the ANOVA analysis of the suggested model (main effect), a $p$-value of 0.04 showed significant results $(p<0.05)$ with an F-value of 48.36 . 

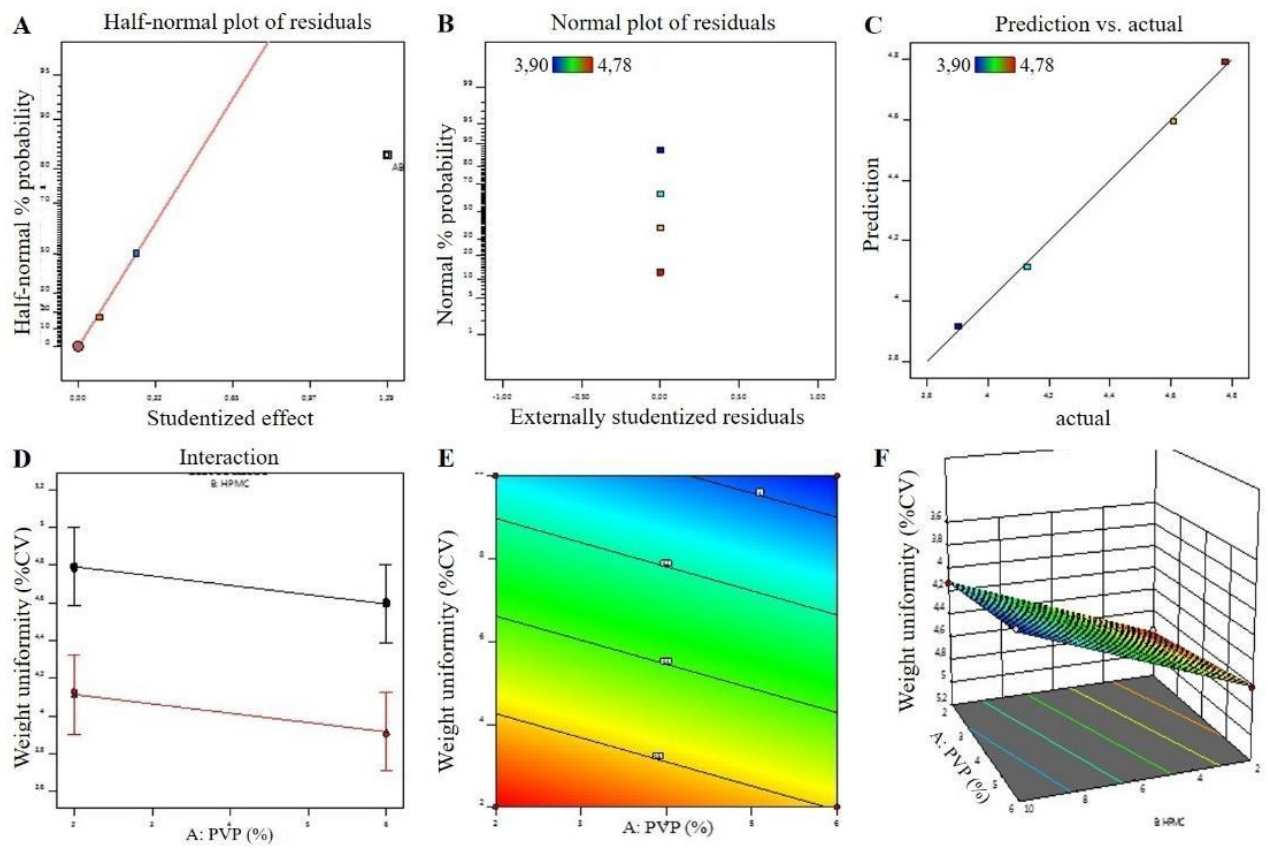

Fig. 1. Model analysis results for the weight uniformity response, (a) half-normal plot, (b) normal plot of residuals curve, (c) prediction vs. actual curve, (d) interaction, (e) contour plot, and (f) 3D surface plot

The actual vs. prediction curve is used to detect values, or groups of values, that are not easily predicted by the model. The actual and predicted values of $\mathrm{R}_{1}$ could be seen in (Fig. 1c) with adjusted $R^{2}$ and predicted $R^{2}$ difference indicators of 0.9984 (less than 0.02). The influence of factors and interactions on the resulting patch weight values are different, because the higher the HPMC concentration, the thickness will increase. Therefore, the resulting patch is getting thicker, thereby increasing its weight [26]. Run experiments 1 and 4 with high levels of HPMC concentrations produced the most massive patch weights. PVP, combined with HPMC, will increase viscosity. The character of PVP is very liquid so that variations in polymer concentration between PVP and HPMC are needed to form a gel (the initial stage in formulation).

The interaction curve in Fig. 1d indicates that low and high PVP concentrations with low and high HPMC concentrations produce the same weight uniformity. The contour plot graph (Fig. $1 \mathrm{e})$, in the green area, indicates that the \%CV value is greater than the blue area. The higher the $\% C V$ value, the less uniform the patch weight is. High-level PVP and low-level HPMC can reduce the \%CV response indicated by the blue area. High PVP concentrations and low HPMC tend to increase $\% \mathrm{CV}$, as indicated by the middle green area. Based on the regression equation, $\mathrm{R}_{1}$ in Table 2 gives a picture of the effect of each component of the material as a factor in the weight uniformity response. PVP (A), HPMC (B) polymers affect increasing the weight uniformity produced by the smaller \%CV value. The interaction between PVP and HPMC can increase uniformity by decreasing the percentage of PVP and HPMC.

\subsection{Analysis of Thickness Response $\left(\mathbf{R}_{2}\right)$}

Based on the ANOVA analysis of the suggested model, the $p$-value of $0.02(p<0.05)$ showed significant results on the model with an F-value of 49.69 and the dominant factor AB interaction. The unit for evaluating patch matrix thickness is the percent coefficient of variation $(\% \mathrm{CV})$. The drying process at an uneven temperature of $25-30 \mathrm{C}$ and manual patch cutting has more effect on the uniformity of the resulting matrix thickness. All statistical parameters meet the specified requirements to be used in predicting the optimum mixture. The data is normally distributed (Fig. 2a), and the difference between adjusted $R^{2}$ and predicted $R^{2}$ is less than 0.02 (Fig. 2c). 

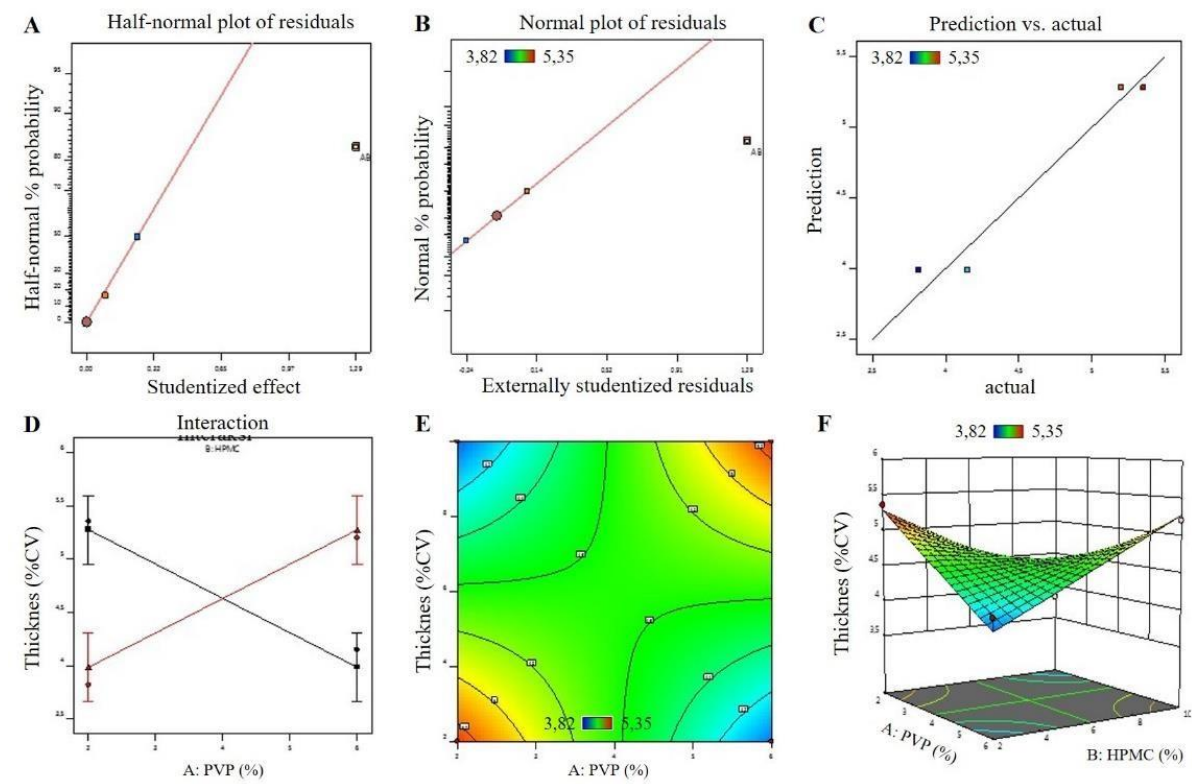

Fig. 2. Model analysis results for thickness response, (a) half-normal plot, (b) normal plot of residuals curve, (c) prediction vs. actual curve, (d) interaction, (e) contour plot, and (f) 3D surface plot

The interaction between the two factors results in two crossing lines, indicating variations in each factor's level of produce \% CV at the same point (Fig. 2d). The contour plot graph (Fig. 2e) shows the green area, which means the concentration of each factor results in a smaller $\% \mathrm{CV}$ value in the same range. There is a slight yellow in the low concentration PVP area and a low concentration HPMC and tiny blue.

\subsection{Analysis of Swelling Index Response $\left(\mathbf{R}_{3}\right)$}

The model obtained has a significant status $(p<0.05)$ with reduced type $2 \mathrm{FI}$, and the dominant factor is $\mathrm{AB}$ interaction. The response of the development index is a critical point in determining polymers, and it is crucial to predict the release of active substances. PVP polymers are soluble in ethanol but absorb water, so they have an excellent expanding ability. While HPMC has a solubility in water and ethanol with a ratio of 1:1 can bind hydrogen in intramolecular and intermolecular structure [27]. The hydrogen bonds formed next bind to water so they can form hydrogels.
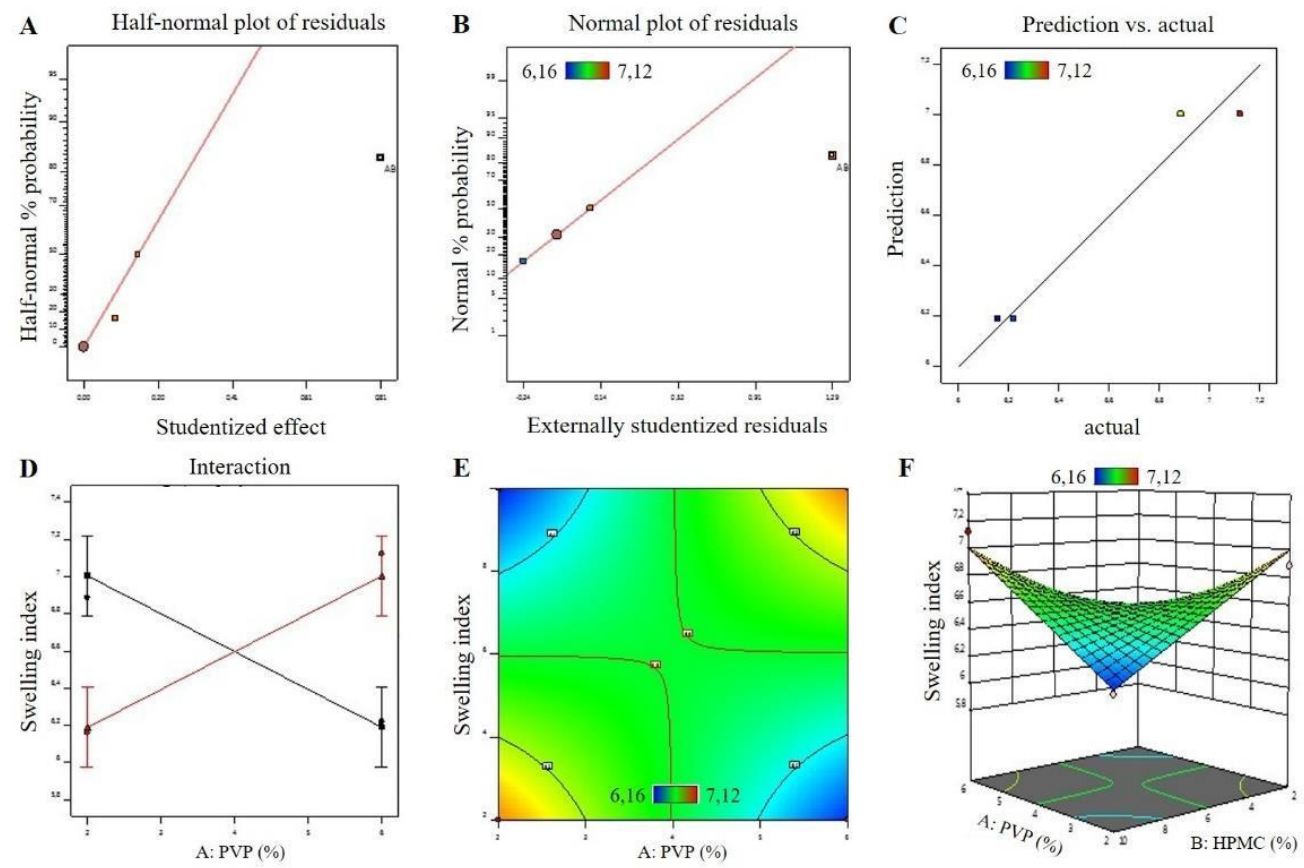

Fig.3. The results of the model analysis for the swelling index response, (a) half-normal plot, (b) normal plot of residuals curve, (c) prediction vs. actual curve, (d) interaction, (e) contour plot, and (f) 3D surface plot 
Data are scattered around diagonal lines on the normal plot of residuals curve (Fig. 3a), indicating the data are normally distributed and qualify for the ANOVA test. The absence of suggestions for transformation also marks this. The interaction scheme between the two factors shows that there are two crossing lines, which means that each factor's level variation produces $\% \mathrm{CV}$ at the same point. The contour plot graph shows a large green area, which means the concentration of each factor results in the \%CV values in the same range and slightly yellow in the low concentration PVP area and low concentration HPMC and blue color the contour plot on the PVP and HPMC sides.

Prediction and actual curves are used to detect values, or groups of values, that are not easily predicted by the model. The actual and predicted values of the development are not very different (Fig. 3c). The development response has an $R^{2}$ of 0.9574 , and adjusted $R^{2}$ - predicted $R^{2}$ difference of 0.11 and an adequate precision value of 9.48. The influence of factors and interactions on the value of the resulting swelling index is different; this is because the higher the concentration of HPMC, the higher the swelling index, the resulting matrix patch thicker so that it increases the value of its development [26].

\subsection{Analysis of Moisture Response $\left(\mathbf{R}_{4}\right)$}

Moisture response has an $R^{2}$ of more than 0.7 (0.9581), the difference between adjusted $R^{2}$ and predicted $R^{2}$ is 0.10 , and adequate precision value (9.57). The $p$-value obtained 0.02 showed significant results because of $p<0.05$ with an F-value of 45.77 and the dominant composition of $\mathrm{AB}$. The interaction between the two factors shows that there are two lines from high HPMC concentrations to PVP concentrations, which means that the level variation of each factor results in a \%CV at one point. The contour plot graph shows the green area in the middle and bluer than the other responses. The concentration of each factor produced a value of $\% \mathrm{CV}$ in the same range and slightly yellow in the low concentration PVP area and low concentration HPMC.
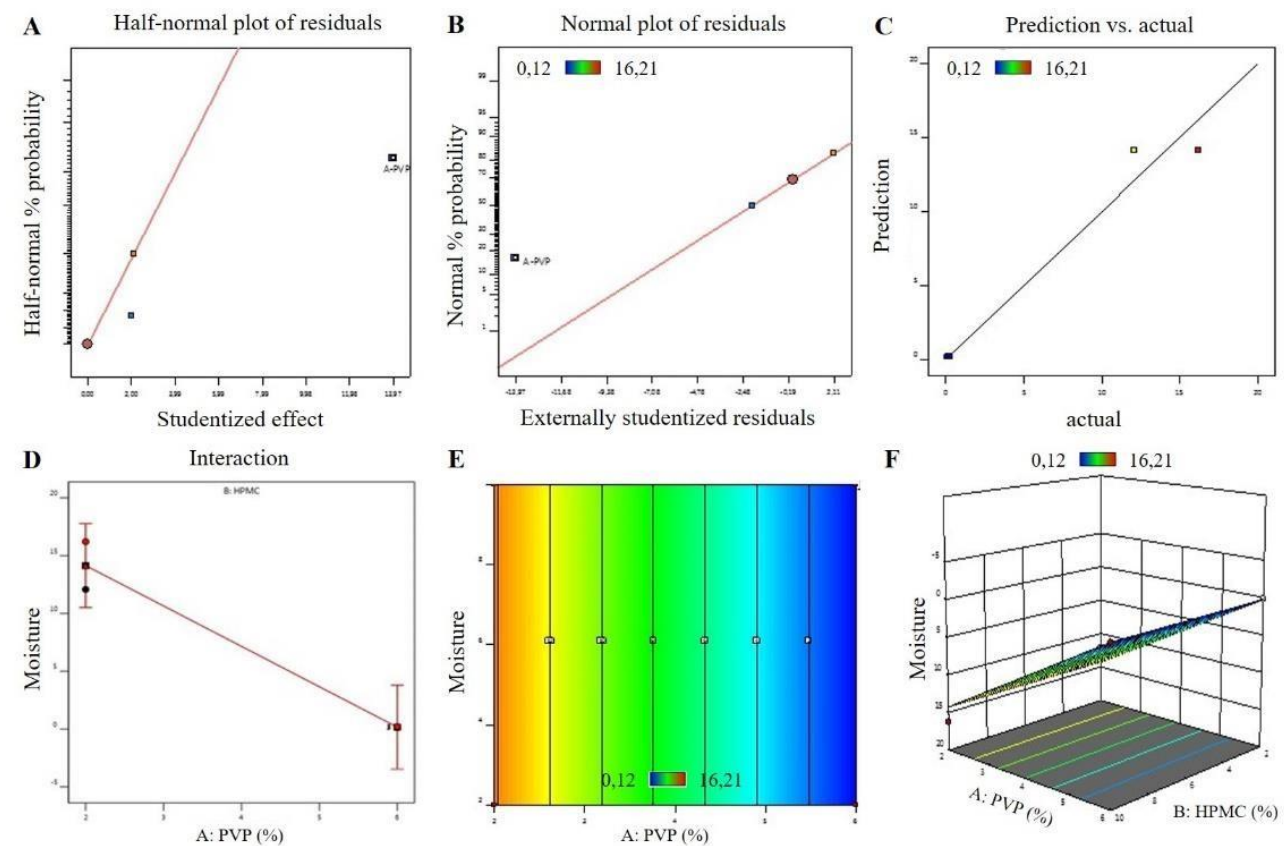

Fig.4. The results of the model analysis for the humidity response, (a) half-normal plot, (b) normal plot of residuals curve, (c) prediction vs. actual curve, (d) interaction, (e) contour plot, and (f) 3D surface

\subsection{Optimum Formula Prediction and Verification}

The desirability value is used as an important indicator in determining the optimum mixture. A desirability value close to 1 signifies closeness to the predicted value. The optimum formula is obtained after the analysis of the suggested model. The optimum formula is obtained by determining each component's priority level, either the independent variable as a factor or response. The model obtained from the factorial design experiment was used to predict an optimum mixture composition in the process of ibuprofen matrix patch formulation. The optimum polymer mixture consists of a PVP concentration of $3.8 \%$ and $2 \%$ HPMC with a desirability value of 0.580 . This mixture will give $\% \mathrm{CV}$ for weight uniformity response of 4.70 , thickness response of 4.69 , swelling index value of 6.64 , and \%CV for the humidity of 7.83 . 
Table 4. Prediction values, observations, and verification range of the optimum formula of the weight uniformity response $\left(\mathrm{R}_{1}\right)$, thickness $\left(\mathrm{R}_{2}\right)$, swelling index $\left(\mathrm{R}_{3}\right)$, and humidity $\left(\mathrm{R}_{4}\right)($ Observation $\pm \mathrm{SD} ; n=6)$

\begin{tabular}{|c|c|c|c|c|c|c|}
\hline Response & Prediction & Observation & $\begin{array}{c}95 \% \text { CI } \\
\text { low } \\
\end{array}$ & $\begin{array}{c}95 \% \text { CI } \\
\text { high }\end{array}$ & $\begin{array}{c}95 \% \text { PI } \\
\text { low } \\
\end{array}$ & $\begin{array}{c}95 \% \text { PI } \\
\text { high }\end{array}$ \\
\hline $\mathrm{R}_{1}$ & 4.70 & $4.37 \pm 0.019$ & 4.45 & 4.96 & 3.41 & 6.00 \\
\hline $\mathrm{R}_{2}$ & 4.69 & $1.55 \pm 0.049$ & 4.30 & 5.09 & 2.34 & 7.05 \\
\hline $\mathrm{R}_{3}$ & 6.64 & $7.19 \pm 0.425$ & 6.37 & 6.90 & 5.08 & 8.20 \\
\hline $\mathrm{R}_{4}$ & 7.83 & $11.43 \pm 0.002$ & 3.36 & 12.29 & -18.70 & 34.35 \\
\hline
\end{tabular}

Verification is based on confidence interval (CI) and prediction interval (PI) values $[23,28]$. The value of $95 \% \mathrm{CI}$ is the range between two values where the value of a sample mean is right in the middle of it. The value of $95 \%$ PI is a value consisting of several values limited by the lower and upper limit values. Uniformity of weights in the optimum formula, \%CV obtained was $4.37 \pm 0.019$, theoretically included in the verification range of $95 \% \mathrm{CI}(4.44-4.95)$ and $95 \%$ PI range (3.40-5.99). The thickness of the optimum formula of 1.55 was included in the 95\% CI verification range (4.29-5.08) and included in the 95\% PI verification range (2.33-7.04). The swelling index and humidity responses have also been verified well. The verification data of observations, CI, and PI can be seen in Table 4 .

\subsection{Evaluate the Optimum Formula}

Swelling tests are carried out to determine the excellent development of polymers to predict the release of active substances. Swelling Index test is done by soaking the patch in phosphate buffer ( $\mathrm{pH}$ 7.4) solution as much as $5 \mathrm{~mL}$. Patch development of up to 5 minutes the patch is smaller because its weight is smaller than the initial weight. The results of development measurements on the optimum formula are $7.19 \pm 0.42$. In theory, the hydrophilic polymer from PVP absorbs water very quickly [29]. The patch matrix in the optimum formula still has an excellent weight uniformity. PVP is hygroscopic, which can absorb ambient air, so the more significant the amount of PVP, the higher the weight.

The optimum patch formula has a $\mathrm{pH}$ of 5, indicating that it is still in the $\mathrm{pH}$ range of the skin declared safe and non-irritating. Criteria for the $\mathrm{pH}$ range that can be tolerated for not irritating the skin is 4.5-6.5. The patch matrix's physical characteristics from the optimum formula are white, have no characteristic odor, and smooth surface conditions. Patch matrices have uniformity in terms of weight and thickness. Moisture test aims to determine the water content in patch preparations that can affect the preparation's stability. High water content can cause contaminants from microorganisms so that the stability of the preparation will be reduced. Moisture test results on the optimum formula values obtained by CV $11.43 \%$, it does not meet the range of requirements. The required water content range is $1-10 \%[12,21,22]$. The effect of PVP is hydrophilic polymers, which have more significant hygroscopic properties than HPMC. The higher the amount of PVP, the percent of humidity will increase. The results of the measurement of humidity in the optimum formula are $11.43 \pm 0.00$.

The folding resistance test shows the strength of the patch in different amounts of polymer. Based on the test results that have been done, the patch matrix on the optimal formula cannot be folded because it is too soft and not elastic, so it does not meet the requirements. This result is caused by the influence of unfavorable preparations so that it can not produce SD and $\mathrm{CV}$ values in this test. Patch preparations are said to be good if the range of folding resistance values is more than 300 times [18].

\subsection{In Vitro Release of Ibuprofen Assay}

Diffusion assay of active patches using cellophane membranes was tested in vitro using a Franz diffusion cell device, with a diffusion area of $\pm 2 \mathrm{~cm}$ and a receptor compartment volume of $15 \mathrm{~mL}$ of solution. The higher the concentration difference will increase the rate of drug diffusion $[17,22]$. In vitro test results indicate the drug is well diffused and released gradually (slowly). Minute 120 has decreased levels of ibuprofen. Drug diffusion release is said to be good if the graph shows an increase in absorbance value in the first minute, then the graph value decreases in the next minute $[17,30]$. 

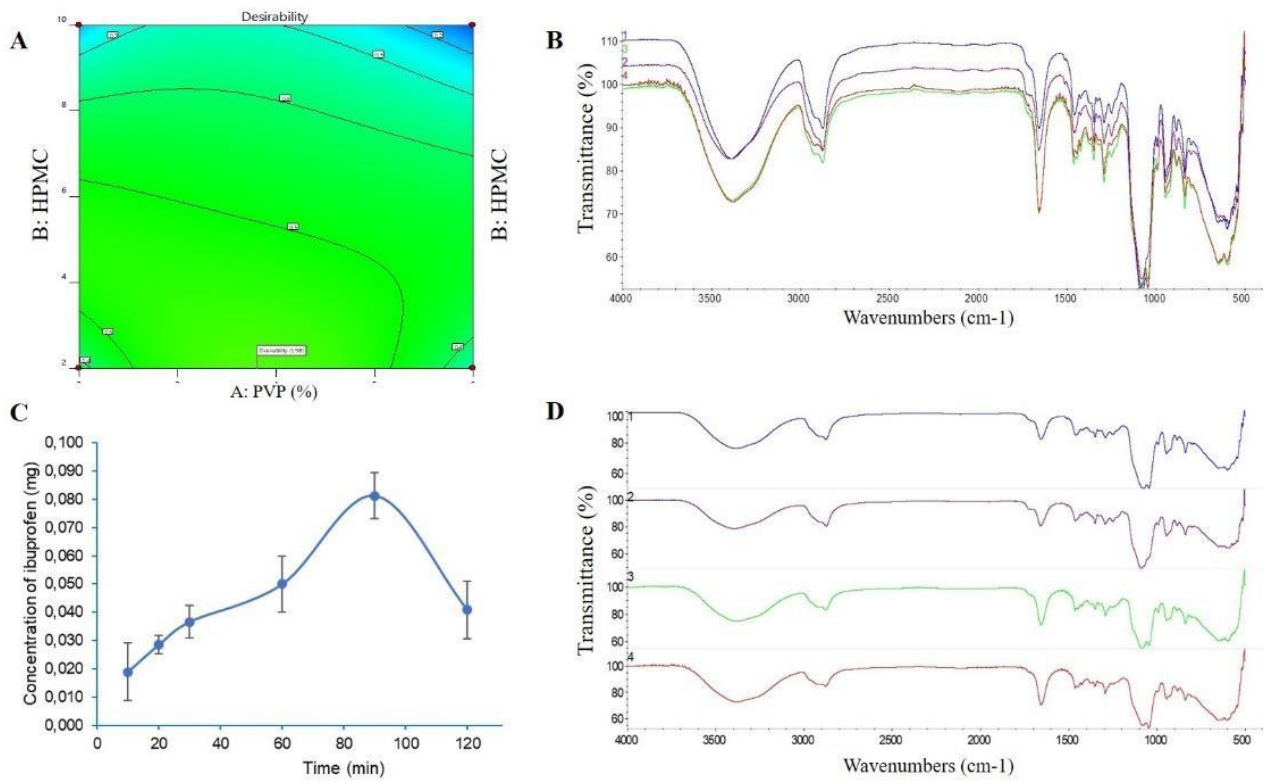

Fig.5. Result of optimum formula, (a) desirability plot, (b) the profile of ibuprofen release in the optimum formula, (c) overlay, and (d) steaking FTIR-ATR spectral of matrix patch using factorial design $2^{2}$

\subsection{FTIR-ATR Spectra Profile of Ibuprofen Matrix Patch}

IR spectra patterns are beneficial in studying interactions between drugs and other components in a formula [24]. Fig. 5c overlays from the four-run experiments show no shift in the spectra pattern at specific wavenumbers. Fig. $5 \mathrm{~d}$ is the profile of each patch matrix produced (steaking from all four runs). Runs 1, 2, 3, and 4 have similar spectra patterns due to the same composition of the constituent materials. However, if seen from the percent transmittance or absorbance value at specific peaks, there is a difference in the absorption. Therefore, further analysis is still needed to perfect the results of this study.

Optimization modeling using factorial design for polymer blends in the ibuprofen patch matrix is excellent. However, the resulting matrix still has some aesthetic shortcomings and pharmaceutical criteria. Poor texture and less elastic become essential points to be developed in further research. Of course, the DoE approach using more advanced techniques will be constructive in modifying variations in the combination of hydrophobic and hydrophilic polymers. It is hoped that a better matrix patch formula will be obtained according to the specified requirements.

\section{CONCLUSION}

The characteristics of transdermal patches produced in variations of PVP and HPMC polymers result in rapid development so that the drug is absorbed to produce pharmacological effects. The optimum concentration of a formula in the resulting patch matrix is PVP $3.8 \%$ and HPMC $2 \%$. Modeling in this optimization can be used in transdermal patch innovations to obtain more perfect results pharmaceutically, aesthetically, and pharmacologically.

\section{ACKNOWLEDGEMENT}

The authors thank the Department of Pharmacy STIKES 'Aisyiyah Palembang and Department of Pharmacy, Faculty of Mathematics and Natural Sciences, Universitas Sriwijaya for support and facilities.

\section{REFERENCES}

1 Madhulatha, A.; Naga, R. T. Formulation and Evaluation of Ibuprofen Transdermal Patches. Int J Res Pharm Biomed Sci 2013, 4 (1), 351-362.

2 Rasool, B.; Abu-Gharbieh, E.; Fahmy, S.; Saad, H.; Khan, S. Development and Evaluation of Ibuprofen Transdermal Gel Formulations. Trop J Pharm Res 2010, 9 (4), 355-363.

3 Prausnitz, M. R.; Langer, R. Transdermal Drug Delivery. Nat Biotechnol 2008, 26 (11), 12611268. 
4 Tombs, E. L.; Nikolaou, V.; Nurumbetov, G.; Haddleton, D. M. Transdermal Delivery of Ibuprofen Utilizing a Novel Solvent-Free Pressure-Sensitive Adhesive (PSA): TEPI@ Technology. J Pharm Innov 2018, 13 (1), 48-57.

5 Ganti, S. S.; Bhattaccharjee, S. A.; Murnane, K. S.; Blough, B. E.; Banga, A. K. Formulation and Evaluation of 4-Benzylpiperidine Drug-in-Adhesive Matrix Type Transdermal Patch. Int J Pharm 2018, 550 (1), 71-78.

6 Tyagi, S.; Goyal, K. Transdermal Drug Delivery System: Quality Approaches and Evaluation. Innov Int J Med Pharm Sci 2017, 2 (3), 15-21.

$7 \quad$ Krishna, M. K.; Nagaraju, T.; Gowthami, R.; Rajashekar, M.; Sandeep, S.; Himabindu, S.; Yamsani, S. K. Comprehensive Review on Buccal Delivery. Int J Pharm 2012, 2 (1), 205-217.

8 Liechty, W. B.; Kryscio, D. R.; Slaughter, B. V.; Peppas, N. A. Polymers for Drug Delivery Systems. Annu Rev Chem Biomol Eng 2010, 1, 149-173.

9 Aghabegi Moghanjoughi, A.; Khoshnevis, D.; Zarrabi, A. A Concise Review on Smart Polymers for Controlled Drug Release. Drug Deliv and Transl Res 2016, 6 (3), 333-340.

10 Kadajji, V. G.; Betageri, G. V. Water Soluble Polymers for Pharmaceutical Applications. Polymers 2011, 3 (4), 1972-2009.

11 Huichao, W.; Shouying, D.; Yang, L.; Ying, L.; Di, W. The Application of Biomedical Polymer Material Hydroxy Propyl Methyl Cellulose (HPMC) in Pharmaceutical Preparations. J Chem Pharm Res 2014, 6 (5), 6.

12 Akram, M. R.; Ahmad, M.; Abrar, A.; Sarfraz, R. M.; Mahmood, A. Formulation Design and Development of Matrix Diffusion Controlled Transdermal Drug Delivery of Glimepiride. Drug Des Devel Ther 2018, 12, 349-364.

13 Cherukuri, S.; Batchu, U. R.; Mandava, K.; Cherukuri, V.; Ganapuram, K. R. Formulation and Evaluation of Transdermal Drug Delivery of Topiramate. Int J Pharm Investig 2017, 7 (1), 10-17.

14 Patel, H.; Patel, U.; Bhimani, B.; Patel, G. Transdermal Drug Delivery System as Prominent Dosage Forms for the Highly Lipophilic Drugs. Int J Pharm Res Bio-Sci 2013, 1 (3), 42-65.

15 Yadav, V. K.; Gupta, A. B.; Kumar, R.; Yadav, J. S.; Kumar, B. Mucoadhesive Polymers: Means of Improving the Mucoadhesive Properties of Drug Delivery System. J Chem Pharm Res 2010, 2 (5), 418-432.

16 Yogananda, R.; Bulugondla, R. An Overview on Mucoadhesive Buccal Patches. Int J Univ Pharm and Life Sci 2012, 2 (2), 348-373.

17 Shabbir, M.; Ali, S.; Raza, M.; Sharif, A.; Akhtar, F. M.; Manan, A.; Fazli, A. R.; Younas, N.; Manzoor, I. Effect of Hydrophilic and Hydrophobic Polymer on in Vitro Dissolution and Permeation of Bisoprolol Fumarate through Transdermal Patch. Acta Pol Pharm 2017, 74 (1), 187-197.

18 Jhawat, V. C.; Saini, V.; Kamboj, S.; Maggon, N. Transdermal Drug Delivery Systems: Approaches and Advancements in Drug Absorption through Skin. Int J Pharm Sci Rev Res 2013, 20 (1), 47-56.

19 Bharkatiya, M.; Nema, R. K.; Bhatnagar, M. Designing and Characterization of Drug Free Patches for Transdermal Application. Int J Pharm Sci Drug Res 2010, 2 (1), 35-39.

20 Ramkanth, S.; Jayaprakash, S.; Vimalakannan, T. Formulation and Evaluation of a Monolithic Drug-in-Adhesive Type Patch Containing Tenoxicam. Int J Pharma Sci Res 2015, 6 (4), 654-659.

21 Prajapati, S. T.; Patel, C. G.; Patel, C. N. Formulation and Evaluation of Transdermal Patch of Repaglinide. ISRN Pharm 2011, 2011, 1-9.

22 Nayak, B. S.; Ellaiah, P.; Pattanayak, D.; Das, S. Formulation Design Preparation and in Vitro Characterization of Nebivolol Transdermal Patches. Asian J Pharm 2014, 5 (3), 175182.

23 Shiyan, S.; Hertiani, T.; Martien, R.; Nugroho, A. K. Optimization and Validation of RPHPLC/UV Detection for Several Compounds Simultaneously in Semi-Purified Extract of White Tea. Rasayan J Chem 2019, 12 (03), 1098-1109.

24 Pratiwi, G.; Martien, R.; Murwanti, R. Chitosan Nanoparticle as a Delivery System for Polyphenols from Meniran Extract (Phyllanthus Niruri L.): Formulation, Optimization, and Immunomodulatory Activity. Int J Appl Pharm 2019, 50-58. 
25 Setyawan, E. I.; Setyowati, E. P.; Rohman, A.; Nugroho, A. K. Central Composite Design for Optimizing Extraction of EGCG from Green Tea Leaf (Camellia Sinensis L.). Int J Appl Pharm 2018, 10 (6), 211-216.

26 Supeni, G.; Cahyaningtyas, A. A.; Fitrina, A. Karakterisasi sifat fisik dan mekanik penambahan kitosan pada edible film karagenan dan tapioka termodifikasi. Jurnal Kimia dan Kemasan 2015, 37 (2), 103-110.

27 Gocho, H.; Shimizu, H.; Tanioka, A.; Chou, T.; Nakajima, T. Effect of Polymer Chain End on Sorption Isotherm of Water by Chitosan. Carbohydr Polym 2000, 41 (1), 87-90.

28 Shiyan, S.; Hertiani, T.; Martien, R.; Nugroho, A. K. Optimization of a Novel KineticAssisted Infundation for Rich-EGCG and Polyphenols of White Tea (Camellia Sinensis) Using Central Composite Design. Int J Appl Pharm 2018, 10 (6), 259-267.

29 Chaudhary, A.; Nagaich, U.; Rastogi, B. Designing and Evaluation of Mucoadhesive Buccal Films of Propranolol Hydrochloride. J Adv Pharm Educ Res 2012, 2 (4), $239-246$.

30 Loftsson, T.; Konrádsdóttir, F.; Másson, M. Influence of Aqueous Diffusion Layer on Passive Drug Diffusion from Aqueous Cyclodextrin Solutions through Biological Membranes. Pharmazie 2006, 61 (2), 83-89.

(C) 2021 by the authors. Submitted for possible open access publication under the terms and conditions of the Creative Commons Attribution (CC BY) license (http://creativecommons.org/licenses/by/4.0/). 